\title{
Microfiltration of Oil-in-water Emulsion Using Modified Ceramic Membrane: Surface Properties, Membrane Resistance, Critical Flux, and Cake Behavior
}

\author{
William de Melo ${ }^{a}$, Giuliana Varela Garcia Lesak ${ }^{a}$, Thamayne Valadares de Oliveira ${ }^{b}$, \\ Fernando Augusto Pedersen Voll ${ }^{a}$, Alexandre Ferreira Santos ${ }^{a}$, Rafael Bruno Vieira ${ }^{b *}$ (]) \\ ${ }^{a}$ Universidade Federal do Paraná, Programa de Pós-Graduação em Engenharia Química, \\ Departamento de Engenharia Química, 89065-300, Curitiba, PR, Brasil. \\ ${ }^{b}$ Universidade Federal de Uberlândia, Faculdade de Engenharia Quimica, 38408-144, \\ Uberlândia, $M G$, Brasil.
}

Received: July 15, 2021; Revised October 22, 2021; Accepted: November 4, 2021

\begin{abstract}
Previous studies have demonstrated the improved membrane properties of ceramic membranes made from thermally modified clays with cationic manioc starch and eggshell residue as additives. Based on the employment of these membranes, the relationship between thermally modified clays' structure and cross-flow microfiltration using oil-in-water emulsion was studied (North Sea heavy crude oil). Using raw clay (M1) and thermally pretreated clay (M2), tubular ceramic membranes were prepared by the extrusion method. Critical Flux in different concentrations $\left(250,500\right.$, and $\left.1000 \mathrm{mgL}^{-1}\right)$, fouling mechanisms, and membrane resistance were analyzed. The initial membrane resistance values for M1 and M2 membranes were $2.23 \pm 0.32 \times 10^{12} \mathrm{~m}^{-1}$ and $1.72 \pm 0.293 \times 10^{12} \mathrm{~m}^{-1}$, respectively. The membrane resistance was reduced by $22 \%$ due to the clay modification, which also decreased the contact angle, increased the pore size, and decreased the membrane roughness. Regarding the total organic carbon removal, the M2 membrane had no loss in separation efficiency despite having a slightly larger pore size. These results indicate that the clay-induced structural changes decreased the membrane resistance and improved the permeate flux but did not decrease the oil-in-water emulsion's separation efficiency.
\end{abstract}

Keywords: oil-in-water emulsion, ceramic membrane, microfiltration, thermal pre-treatment.

\section{Introduction}

The petrochemical, food, leather, and metallurgical industries produce a variety of oily wastewater in the oil refining process. The treatment of oily wastewater is a huge challenge due to its heterogeneous composition and large volumes generated by various industries ${ }^{1}$.

Membrane separation is a rapidly-evolving and commonly-utilized technology with several industrial and pilot-scale applications in oily wastewater treatment ${ }^{1-6}$. Compared with traditional treatment methods, the membranes have presented high oil recovery, low energy demand, and compact design, for example, gravity settling ${ }^{1}$.

Surface charges, electrostatic interactions, size exclusion (i.e., sieving), and selective wettability are factors that influence the treatment of oil-in-water emulsions using membranes? The size exclusion effect allows pressurized water to pass through the membrane while blocking oil droplets larger than the membrane pores ${ }^{8}$.

Because of the presence of surface hydroxyl $(-\mathrm{OH})$ groups of ceramic particles, the ceramic membrane is usually hydrophilic ${ }^{9,10}$. The modification of ceramic membranes in oil-in-water emulsion treatment to improve the permeate flux or decrease membrane fouling has been studied extensively.

* e-mail: rafael.bruno@ufu.br
For example, the studies regarding the application of carbon ${ }^{11}$, mullite and alumina ${ }^{12}$, kaolin, quartz, feldspar, sodium carbonate, boric acid and sodium metasilicate ${ }^{13}$, clay $^{14}$, niobium $^{15}$, calcium carbonate and titanium dioxide ${ }^{16}$, and alumina and activated carbon ${ }^{17}$ in the field of membrane synthesis. Different low-cost additives are employed as banana peel powder ${ }^{18}$. Various elements are used in the synthesis of membranes as observed in these studies; some being comparatively more expensive (e.g., titanium and carbon) and others being less so.

The main drawbacks, as reported in the literature, of using the membrane technologies (microfiltration and ultrafiltration), which work mainly by the size-exclusion principle, are oil fouling, lower permeate flux, and oil content in the permeate ${ }^{19,20}$. The fouling decreases the permeate flux through the deposition mechanisms of particles on the surface (external fouling) or in the membrane's pores (internal fouling $)^{21}$. Unlike the reversible nature of the concentration by polarization, fouling can cause irreversible membrane permeability loss, generating an operational failure ${ }^{22}$.

By tuning the flux of the system, the critical flux concept has been proposed as a mild and facile fouling control method that takes advantage of the transition of a filtration system between non-fouling and particle deposition states ${ }^{23}$. Knowing the critical flux behavior in different concentrations and 
comparing it with different membranes is thus fundamental for applying membranes in separation processes.

For this purpose, low-cost ceramic membranes (with inexpensive raw materials) were successfully prepared by the extrusion method using thermally-treated clays and inexpensive pore-generating and strength-improving agents ${ }^{24-26}$.

According to Xavier et al. ${ }^{26}$, phase transformations suggest that metakaolinite (MKaol) and anorthite can influence the final membrane properties. Among the modifications performed on the clay in these studies, MKaol mixed with Ca-based compounds (from eggshells) that may influence the oil-inwater emulsion separation is the most interesting. Because it is almost entirely amorphous, metakaolin's total silicate and aluminate content is considered completely reactive ${ }^{27}$.

Although membranes prepared by thermally-treated clays have already shown good characteristics (e.g., in terms of porosity and permeability), their systematic investigation in terms of microfiltration, particularly in the oil-in-water emulsion separation, has not been addressed in the literature. This paper aims to investigate and compare the treatment's effect on two different ceramic membranes, prepared with untreated and thermally-treated clays, respectively, in terms of strength, porosity, roughness, and contact angle on cross-flow microfiltration of oil-in-water emulsions. The permeate flux, fouling mechanisms, total organic carbon (TOC) removal, and membrane resistance were studied under different pressure conditions.

\section{Materials and Methods}

\subsection{Membrane}

Faience clay [Cermassas-Pastacer Ltda.] was used as a raw material to produce ceramic membranes. Eggshell residues and cationic manioc starch grade Superion 300 with a degree of substitution in the range of $0.033-0.036 \mathrm{~mol} / \mathrm{mol}$ [Grupo Horizonte-Agrícola Horizonte Ltda. PR/ Brazil] were used as additives.

Natural clay (NC) was dried for $12 \mathrm{~h}$ in an oven and dry ground in a bench ball mill. NC was modified by thermal treatment at $500^{\circ} \mathrm{C}$ for $24 \mathrm{~h}$ with a heating rate of $5^{\circ} \mathrm{C} / \mathrm{min}$. The samples were dry ground in a bench ball mill with alumina balls for $4 \mathrm{~h}$ after the thermal treatment and homogenized with a \#60 Tyler mesh $\left(2.5 \times 10^{-4} \mathrm{~m}\right)$ sieve. Eggshells were also homogenized using the same sieve mesh.

Two tubular ceramic membranes were prepared by extruding raw clay (M1) and thermally-treated clay (M2) to form a porous tubular membrane with the addition of cationic manioc starch $(2.5 \mathrm{wt} \%)$ and eggshell residue $(2.5 \mathrm{wt} \%)$, using an extruder (MVIG-75, Gelenski). The tubular ceramic membranes were then sintered at $1100^{\circ} \mathrm{C}$ for $30 \mathrm{~min}$ with a $5^{\circ} \mathrm{C} / \mathrm{min}$ ramp. The tubular membranes had an outer diameter of $1.88 \times 10^{-2} \mathrm{~m}$, an inner diameter of $1.07 \times 10^{-2} \mathrm{~m}$, a wall thickness of $4.05 \times 10^{-3} \mathrm{~m}$, and a length of $2.00 \times 10^{-1} \mathrm{~m}$.

The morphology of the elaborated membrane was observed by scanning electron microscopy (SEM) operating at $10 \mathrm{kV}$ (Tescan, LMU; model, Vega 3) coupled to an energy-dispersive detector (EDS). Before their characterization, the membranes were fractured and metalized by sputtering with a thin gold layer. The contact angle between water and the membrane was measured using a contact angle goniometer (CA, OCA
15 Dataphysics, Germany) with deionized water; $10 \mu \mathrm{L}$ of water droplets were used for contact angle measurements $\left(\mathrm{T}=25^{\circ} \mathrm{C}\right)$. The contact angle of each membrane was measured five times to minimize the experimental errors and the average value was reported. Atomic Force Microscopy (AFM) analyses were performed using an SPM-9600 (Shimadzu) in Dynamic Force Mode (Tapping Mode) / Amplitude Modulation Mode and cantilevers procured from BudgetSensors (TAP 190AL). The scanning scale was $5 \mu \mathrm{m} \times 5 \mu \mathrm{m}$. A Gwyddion software (http://gwyddion.net/) was employed to calculate the membrane surface roughness. Mercury porosimetry was performed on a mercury porosimeter, model Autopore IV $9500 \mathrm{~V} 1.07$, at $130^{\circ}$ contact angle and 485 dynes $/ \mathrm{cm}$ surface tension.

\subsection{Oil-in-water emulsion}

Oil-in-water emulsions were prepared following the same procedure. About 250, 500, and $1000 \mathrm{mg}$ of oil (North Sea heavy crude oil) was added in 1L of deionized water, and the mixture was stirred for $8 \mathrm{~min}$ at $14000 \mathrm{rpm}$ in a high-speed mechanical agitator. Table 1 summarizes the main characteristics of this oil. Saturates, Aromatics, Resins, and Asphaltenes (SARA) analysis of this crude oil was based on a standard chromatographic procedure. Details of the characterization can be found in Simon et al. ${ }^{28}$. The emulsion's stability was evaluated using turbidity and was found to be stable throughout the experiments.

\subsection{Filtration apparatus}

The filtration experiments were conducted from the inside to the outside of the membrane. The experimental setup used for the filtration tests included one feed tank with $1 \mathrm{~L}$ capacity (T-01), a pump (B-01) controlled by a power supply, a manometer (PEI-01), a balance to measure permeate mass, a beaker to collect the permeate (T-02), a membrane module (M-01), and a valve (V-01). Figure 1 is the schematics of the apparatus.

\subsection{Evaluation of the membrane performance}

Filtration experiments were conducted to determine the hydraulic permeability and emulsion retention in tubular ceramic membranes (from the inside to the outside). All the membranes were compacted with deionized water at 1 bar for $30 \mathrm{~min}$ before use to remove any loose particles that may have remained in the filtration media. During the

Table 1. Summary of crude oil properties.

\begin{tabular}{lc}
\hline \multicolumn{1}{c}{ Parameters } \\
\hline$\rho\left(g \mathrm{~cm}^{-3}\right)\left(15^{\circ} \mathrm{C}\right)$ & 0.939 \\
\hline$\rho\left(g \mathrm{~cm}^{-3}\right)\left(65^{\circ} \mathrm{C}\right)$ & 0.906 \\
\hline$\mu(\mathrm{mPa} . \mathrm{s})\left(65^{\circ} \mathrm{C}\right)$ & 20.4 \\
\hline SARA $(\mathrm{wt} \%)$ & 37 \\
\hline Saturated & 44 \\
\hline Aromatics & 16 \\
\hline Resins & 2.45 \\
\hline Asphaltenes & 0.040 \\
\hline water content $(\%)$ &
\end{tabular}




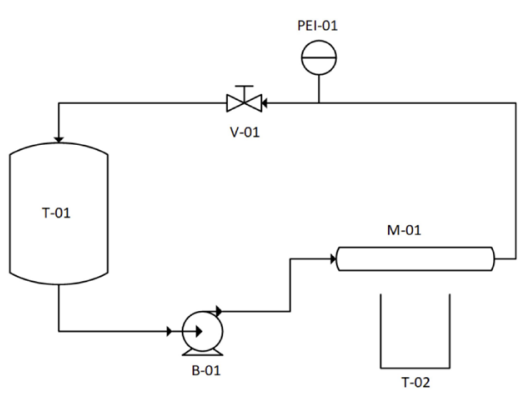

Figure 1. Filtration system.

experiments, the operating conditions were maintained at a volumetric flow rate of $6.94 \times 10^{-5} \mathrm{~m}^{3} \cdot \mathrm{s}^{-1}$, a pressure of $0.2-1.4$ bar, and a temperature of $25^{\circ} \mathrm{C}$. The permeate flux, $\mathrm{J}\left(\mathrm{L} m^{-2} h^{-1}\right)$, was determined under different pressures, according to Equation 1.

$J=\frac{V_{p}}{A_{p} t}$

$\mathrm{V}_{p}$ is the volume of the permeate $(\mathrm{L}), A_{p}$ is the membrane area $\left(\mathrm{m}^{2}\right)$, and $\mathrm{t}$ is the operating time $(\mathrm{h})$.

\subsection{Critical flux}

For the critical flux experiments, the permeate flux was evaluated with deionized water performed with increasing pressures at seven different pressures with a step time of $3 \mathrm{~min}$. Subsequently, the oil-in-water emulsion was fed into the system and the critical flux was determined using the same stepping procedure. The flux behavior was evaluated using a plot of permeate flux $(\mathrm{J})$ vs. pressure.

\subsection{TOC removal}

The TOC removal was analyzed (Equation 2). Carbon measurements were performed on a Shimadzu TOC-L total organic carbon analyzer.

$$
R(\%)=\left(1-\frac{T P}{T A}\right) \times 100
$$

The TOC content in the feed (TA) was $714 \mathrm{mgL}^{-1}$ for the oil-in-water emulsion $\left(1000 \mathrm{mgL}^{-1}\right)$ obtained. TP represents the TOC content in the permeate, in $\mathrm{mgL}^{-1}$. The measurement of the TOC was carried out according to the Methods Standard.

\subsection{Resistance}

\subsubsection{Membrane resistance $\left(R_{m}\right)$}

The membrane resistance was determined using the slope of the pure water permeate flux vs. the transmembrane pressure (TMP) plot. The initial membrane resistance is given using Darcy's law:

$$
J_{w 0}=\frac{T M P}{\mu R_{m}}
$$

$\mathrm{J}_{\mathrm{w} 0}$ is the instantaneous permeate flux $\left(\mathrm{ms}^{-1}\right)$ and $\mu$ is the dynamic water viscosity ( $\mathrm{Pa} \mathrm{s}$ ).

\subsubsection{Total Resistance $\left(R_{l}\right)$}

To analyze the fouling mechanisms, we measured and calculated the total resistance using Equation 4.

$$
R_{T}=\frac{T M P}{\mu J}
$$

$\mathrm{R}_{\mathrm{T}}$ is the total resistance $\left(\mathrm{m}^{-1}\right)$, TMP is the transmembrane pressure (bar), $\mathrm{J}$ is the permeate flux $\left(\mathrm{L} \mathrm{m}^{-2} h^{-1}\right)$, and $\mu$ is the dynamic viscosity of water at $25^{\circ} \mathrm{C}\left(0.8937 \times 10^{-3} \mathrm{~Pa} . \mathrm{s}\right)$.

\subsection{Study of the fouling mechanism}

The modification of the classical general equation of the Hermia model results in the following general equation (Equation 5) for cross-flow microfiltration ${ }^{29-31}$ :

$-\frac{d J}{d t}=k\left(J_{s s}-J\right) J^{2-n}$

$\mathrm{J}$ is the permeate flux, $\mathrm{J}_{\mathrm{ss}}$ is the steady-state permeate flux, $\mathrm{t}$ is the filtration time, $\mathrm{k}$ is the resistance coefficient, and $\mathrm{n}$ is the blocking index. The four membrane fouling mechanisms are the complete blocking model $(n=2)$, standard blocking model $(\mathrm{n}=1.5)$, intermediate blocking model $(\mathrm{n}=1)$, and cake filtration model $(\mathrm{n}=0)$.

The model parameters $\left(\mathrm{k}, \mathrm{J}_{\mathrm{ss}}\right.$, and $\left.\mathrm{n}\right)$ were estimated by minimizing the sum of the squared errors between the calculated and the experimental values of $\mathrm{J}$.

$O F\left(k, J_{s S}, n\right)=\sum_{i=1}^{N E}\left(J_{i}^{\text {exp }}-J_{i}^{\text {calc }}\right)^{2}$

$N E$ is the number of the experimental points used in the parameter estimation, $O F$ is the objective function, $J_{i}^{\text {calc }}$ is the calculated permeate flux, and $J_{i}^{e x p}$ is the experimental permeate flux.

All simulations, parameter estimation, and statistical analyses were performed in Scilab. The function "ode" was used to solve the initial value problem defined by the ordinary differential equation (Equation 5) associated with its initial condition. The function "fminsearch" was used to minimize the objective function presented in Equation 6 using the Nelder-Mead algorithm. The parameter uncertainties were calculated using the methodology described by Bainy et al. ${ }^{32}$. The blocking index and its expanded uncertainty (at 95\%) were used to identify each membrane's most probable fouling mechanism.

\section{Results and Discussion}

\subsection{Characterization of the membranes}

\subsubsection{SEM and EDS}

The M2 membrane underwent thermal pretreatment before sintering, which was the main difference between the M1 and M2 membranes. A modification primarily in the kaolinite occurred during this pretreatment, according to the reaction: 


$$
\mathrm{Al}_{2} \mathrm{Si}_{2} \mathrm{O}_{5}(\mathrm{OH})_{4}(\mathrm{Kaol}) \rightarrow \mathrm{Al}_{2} \mathrm{Si}_{2} \mathrm{O}_{7}(\mathrm{MKaOl})+2 \mathrm{H}_{2} \mathrm{O}
$$

According to the results presented by Xavier, et al., $2019^{26}$, the presence of amorphous MKaol rather than crystalline Kaol in thermally-treated clays may be responsible for improving the ceramic membranes' final performance.

SEM analyses were carried out on the ceramic membrane (M1 and M2) surfaces to verify the microstructure (Figure 2).

The SEM images clearly reveal that the thermally-treated clay significantly affects the morphology of the membrane. The membrane structures (M1 and M2) are characterized by irregularly distributed pores with a relatively complex shape. Moreover, a cursory observation of the SEM revealed no macrodefects such as cracks. The M2 membrane's structure was slightly more porous (yellow circle). The EDS identified similar percentages of $\mathrm{Si}, \mathrm{Al}$, and $\mathrm{O}$ in the membranes. These membrane attributes make it suitable for microfiltration applications ${ }^{33}$. Heat treatment of kaolinite altered the atomic structure, which had a high impact on macroscopic properties such as surface wettability ${ }^{34}$.

\subsubsection{Pore size}

The pore size of the membranes was analyzed using $\mathrm{Hg}$ intrusion, as shown in Figure 3(a).

The pore size distributions (SDs) for M1 and M2 in Figure 3(a) show that the pores with diameters ranging from
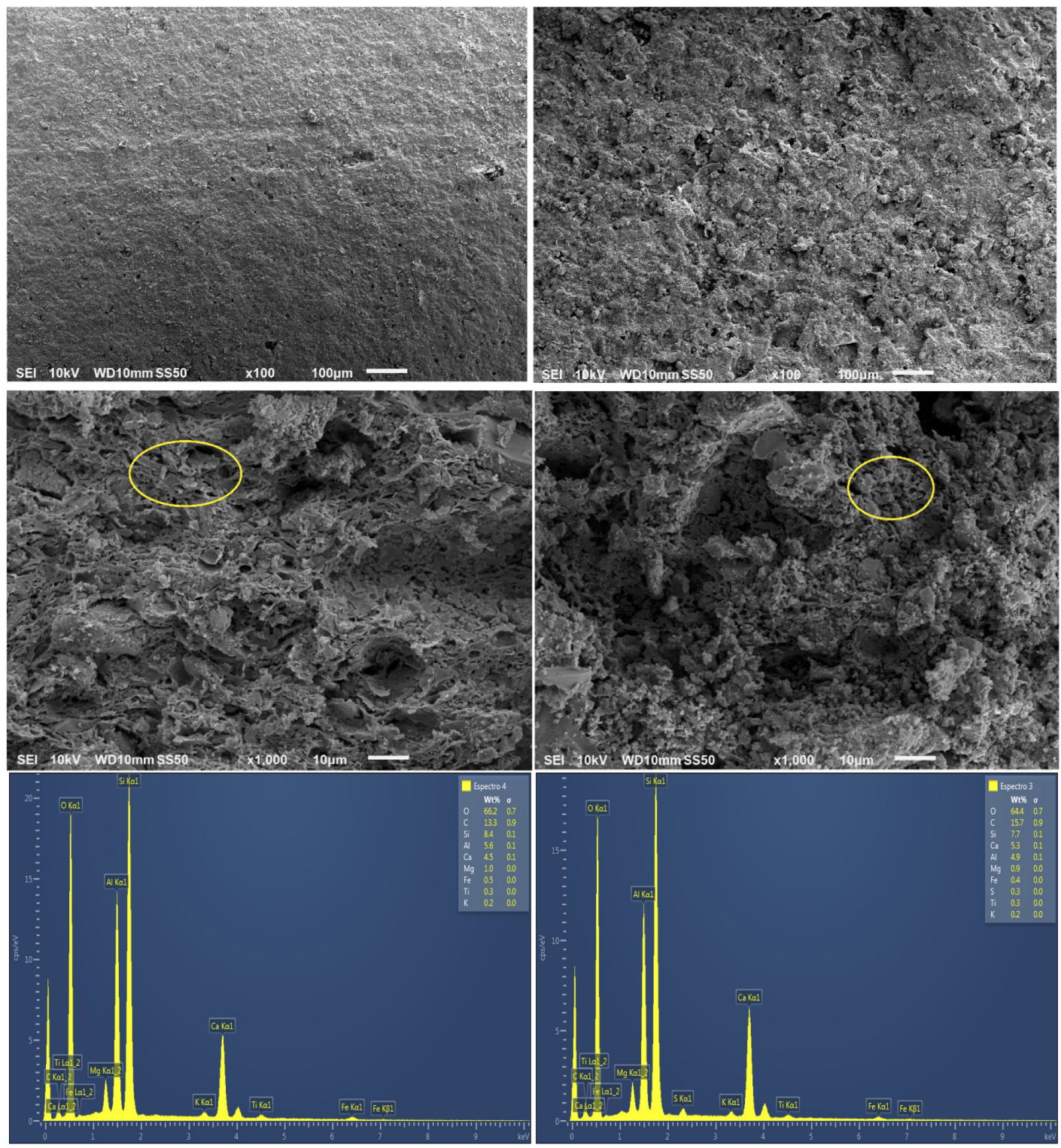

\section{M1 membrane}

M2 membrane

Figure 2. SEM micrographs and EDS of M1 and M2 membranes. 


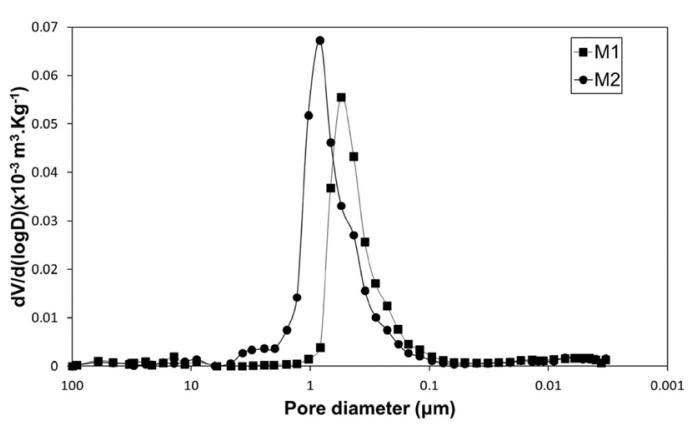

(a)

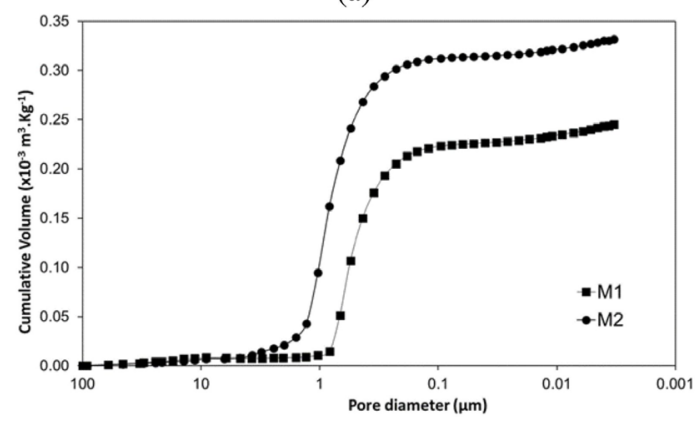

(b)

Figure 3. (a) pore size distribution and (b) cumulative volume for M1 and M2 membranes.

$1 \times 10^{-7}$ to $1 \times 10^{-6} \mathrm{~m}$ were predominant in M1. However, most pores in $\mathrm{M} 2$ had a diameter ranging from $1 \times 10^{-7}$ to $4 \times 10^{-6} \mathrm{~m}$. The M2 membrane had a larger mean pore size and a broader pore SD than the M1 membrane. The average pore diameter of the ceramic membrane for M1 and M2 membranes are $0.51 \mu \mathrm{m}$ and $0.82 \mu \mathrm{m}$, respectively. The ceramic membranes can be classified as microfiltration membranes based on their average pore diameter. Using zeolite membranes (NaY/alumina) in the process of oil-water separation, Barbosa et al..$^{35}$ obtained an average pore diameter and a porosity of $0.714 \times 10^{-6} \mathrm{~m}$ and $33.37 \%$, respectively.

The porosity of the M1 membrane is $42.6 \%$ while that of the M2 membrane is $48.4 \%$ (as measured by $\mathrm{Hg}$ porosimetry). This increase in porosity may possibly be due to an increase in the pores' number or size resulting from the thermal treatment of the clay. The porosimetry results are consistent with the SEM images (Figure 2). More porous membranes have a lower water contact angle in general ${ }^{36}$. Porosity directly affects the surface roughness, resulting in a change in wettability ${ }^{34}$.

\subsubsection{AFM analysis of the membranes and contact angle}

The hydrophilicity of the ceramics was characterized by contact angle measurement. The wettability properties of M1 and M2 membranes were measured in terms of contact angle to determine the thermal treatment's effectiveness. Figure 4 presents the values of the contact angle of M1 and M2 membranes. As shown, contact angle values below $30^{\circ}$ were obtained for the membranes due to the high hydrophilicity

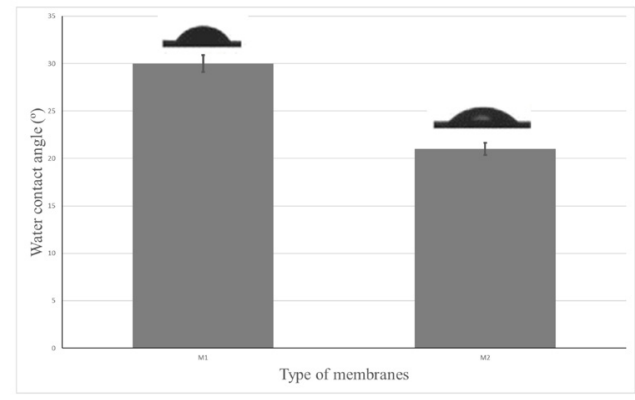

Figure 4. Contact angle of membranes.

of the membranes. The thermal pretreatment led to a decrease in the contact angle, making the membrane more hydrophilic. The kaolinite's overall macroscopic wettability was highly influenced after dehydroxylation ${ }^{34}$. The clay's pretreatment possibly enabled further dehydroxylation of kaolinite, which improved the membrane's wettability.

Hubadillah et al. ${ }^{37}$ employed the kaolin hollow fiber membrane (KHFM) and showed that the highest contact angle was $33^{\circ}$, still in the range of hydrophilicity behavior that a $\mathrm{KHFM}$ sintered at $1500^{\circ} \mathrm{C}$ possessed.

From Figure 5, the maximum feature height $(\mathrm{Sz})$ of the M1 membrane is about $0.84 \mu \mathrm{m}$ while that of the M2 membrane is $1.06 \mu \mathrm{m}$.

According to the AFM analysis, the average roughness and the square mean roughness for the M1 and M2 membranes were $97.5 \mathrm{~nm}, 124.8 \mathrm{~nm}, 71.3 \mathrm{~nm}$, and $91.9 \mathrm{~nm}$, respectively. These results reveal that there was a decrease in the M2 membrane's average roughness, which may have enhanced the increase in the permeate flux.

Increased roughness can lead to two changes in the membrane, namely, an increased effective filtration area and a decreased membrane's antifouling performance ${ }^{38}$.

Water molecules can permeate easily through the membranes as they are porous. The modified clay was responsible for the increased porosity of the membrane (Figure 2), which improved the permeate flux. Furthermore, the reduced roughness improved the membrane's antifouling properties. The fouling is due to possible contaminant (organic or inorganic) accumulation on the deeper valleys of the rough membrane surface ${ }^{2}$. According to Wenzel, increasing the roughness of a solid surface increases the surface tensions at the solid-liquid and solid-vapor interfaces, while the interfacial surface tension of the liquid-vapor remains constant ${ }^{39,40}$. Consequently, a higher contact angle is achieved to balance the increased surface tension due to the surface roughness increase ${ }^{39}$.

\subsubsection{Resistance}

Modifications on the ceramic membrane had a more significant influence on the resistance. For the M1 and M2 membranes, the membrane resistance (Equation 3) values were $2.23 \pm 0.320 \times 10^{12} \mathrm{~m}^{-1}$ and $1.72 \pm 0.293 \times 10^{12} \mathrm{~m}^{-1}$, respectively. The clay modification resulted in a $22 \%$ reduction in the membrane resistance possibly due to the decreased contact angle, increased pore sizes, and slightly decreased 

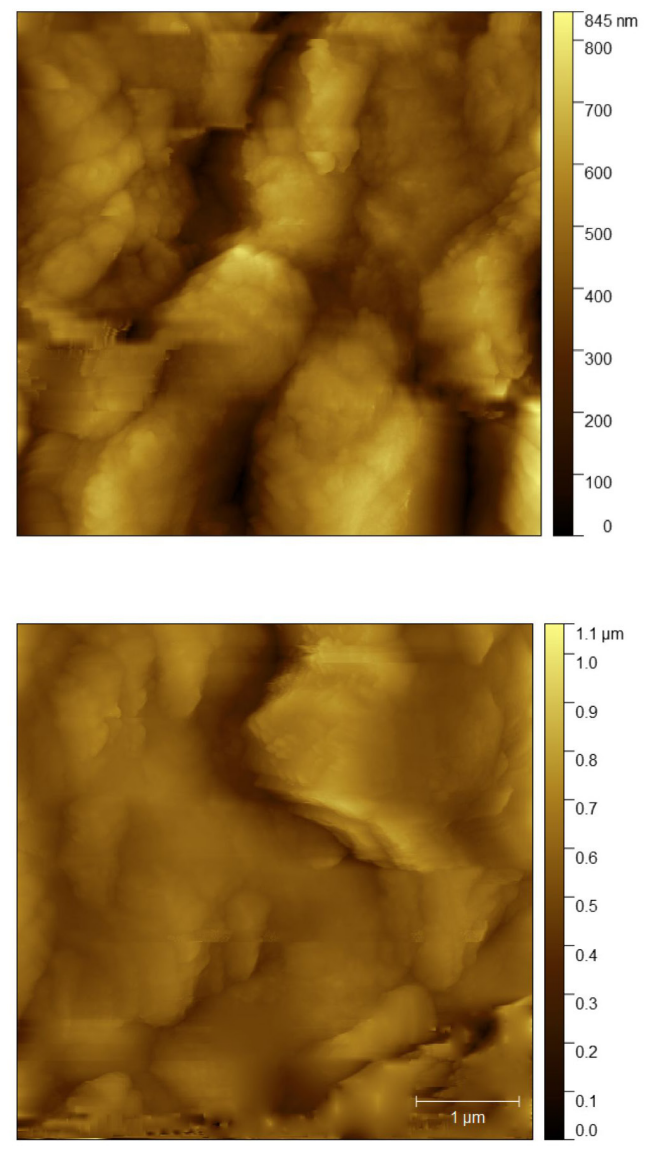

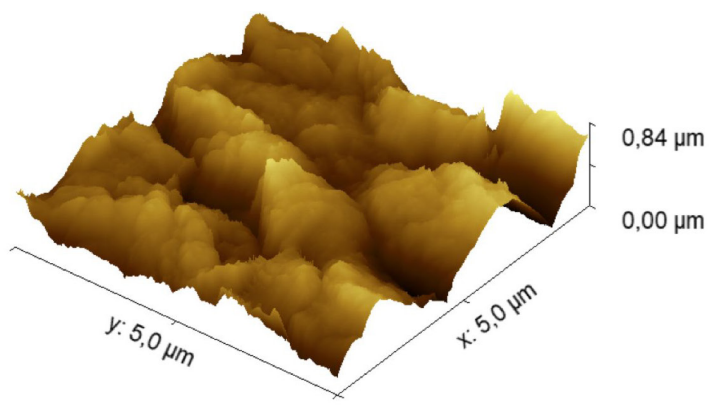

(a)

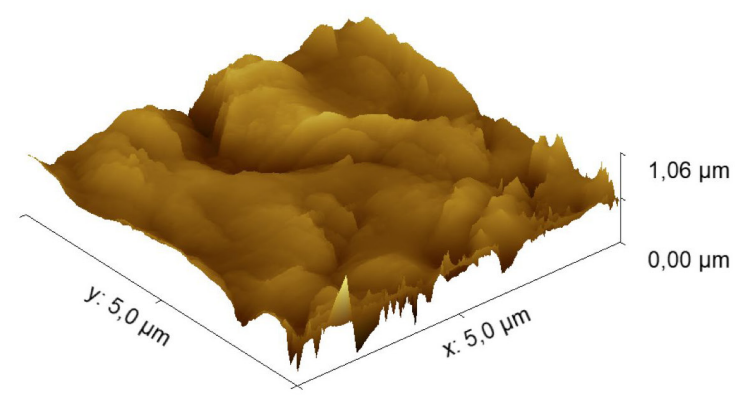

(b)

Figure 5. Surface profiling of the (a) M1 and (b) M2 membranes.

roughness. The values obtained for the membrane in this study were somewhat higher than the previously reported values.

Fang et al. ${ }^{41}$ verified that the membrane resistance for an oil-in-water emulsion purification with membranes made from spherical fly ash with an average pore size of $0.77 \mu \mathrm{m}$ was $0.16 \times 10^{11} \mathrm{~m}^{-1}$. Nandi et al. ${ }^{13}$ reported that employing ceramic membranes made of kaolin, quartz, feldspar, sodium carbonate, boric acid, and sodium metasilicate obtained an intrinsic membrane resistance of $9.26 \times 10^{11} \mathrm{~m}^{-1}$ and a hydraulic pore diameter of $0.51 \mu \mathrm{m}$.

\subsection{Microfiltration}

\subsubsection{Critical flux}

Experiments were performed with different emulsion concentrations $\left(250,500\right.$, and $\left.1000 \mathrm{mgL}^{-1}\right)$ and pure water to verify the behavior of the membranes with respect to the microfiltration by oil-in-water emulsion. Figures 6 and 7 show the critical flux results for the M1 and M2 membranes, respectively, under different conditions.

There are two distinct forms of critical flux: strong and weak $^{42}$. The former is related to the pure water line behavior's
TMP deviation, and the latter is identified by the point at which the flux-TMP linear relation, which is below the pure water line due to the initial fast fouling, ceases ${ }^{43}$.

The definitions of the weak and strong forms of the critical flux require that the total resistance does not vary with time in the fluxes below the critical flux. However, in some cases, constant resistance during filtration may never be achieved, even at extremely low fluxes ${ }^{44}$.

One possible explanation of Figures 6 and 7 is that at lower concentrations, an oil layer formed on the membrane surface can be removed by the hydrodynamic action of the flux. However, at higher concentrations, the hydrodynamic action cannot remove the oil layer. By increasing the pressure, this layer becomes thicker, and the flux decreases.

As seen in Figure 6, both forms of critical flux are observed for the M1 membrane, depending on the feed concentration. The strong form can be identified for the $250 \mathrm{mgL}^{-1}$ condition while the weak form can be observed for the 500 and $1000 \mathrm{mgL}^{-1}$ conditions. We can see that the M1 membrane can only operate without fouling at lower feed concentrations (considering the studied ones) and that 
increasing the feed oil concentration results in greater fouling even at lower TMP.

Figures 6 and 7 depict that the permeate flux of the M2 membrane was closer to the behavior of pure water than that of the M1 membrane, which deviated significantly from the behavior of water.

In percentage terms, the M2 membrane had a maximum reduction in a permeate flux (deviation from the behavior of pure water) of $22.6 \%$ for a concentration of $1000 \mathrm{mgL}^{-1}$ at 0.6 bar. Meanwhile, the M1 membrane had a $52.5 \%$ reduction in permeate flux. At a concentration of $1000 \mathrm{mgL}^{-1}$, the maximum reduction for $\mathrm{M} 1$ and $\mathrm{M} 2$ was $57.2 \%$ and $38.2 \%$, respectively, at the maximum pressure studied (1.4 bar). These results reveal that the M2 membrane had a smaller reduction in permeate flux (deviation from the behavior of pure water) than the M1 membrane.

The results indicate that both cross-flow shear and droplet coalescence mitigate membrane fouling by an oil emulsion; the latter is more typical of oil emulsion foulants than solid particles. A gap exists in the vast database of knowledge accumulated for membrane-based oil-in-water separations, with regards to critical flux, which is a function of various parameters and provides crucial operational and design heuristics of the oil emulsion ${ }^{45}$.

\subsubsection{Fouling experiments}

Experiments were performed to verify the fouling characteristics of the membranes at a concentration of

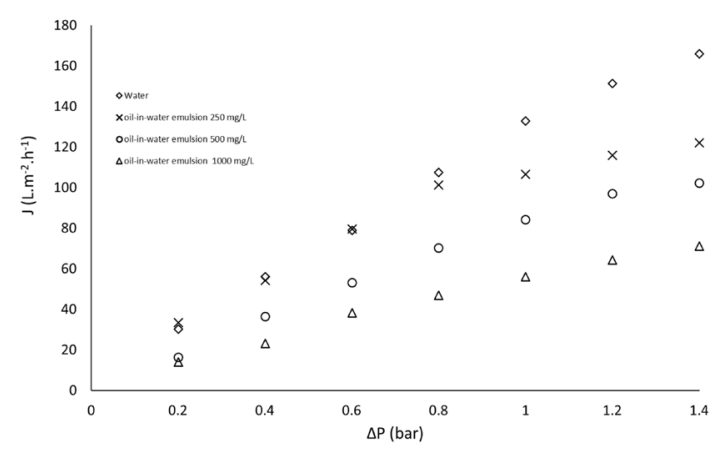

Figure 6. Permeate fluxes in different pressures for M1 membrane under different conditions.

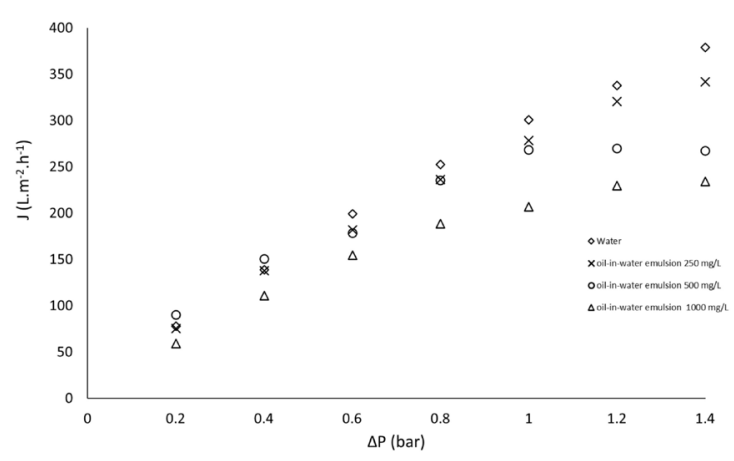

Figure 7. Permeate fluxes in different pressures for M2 membrane under different conditions.
$1000 \mathrm{mgL}^{-1}$ because the emulsion behavior of both the membranes deviates significantly from pure water under this condition.

Figures 8 and 9 present the time variation in permeate flux for the membranes (M1 and M2) at different values of $\Delta \mathrm{P}$. The rate of flux decline is higher at higher pressures, as evidenced in the obtained results. The greater amount of oil penetration in the membrane pores (that can occur even when the oil droplet size is bigger than the pore diameter $)^{46}$, the quicker formation of oil layer over the surface, and the cake layer compaction, all of which account for fouling increase, are possible reasons for this trend.

An increase in TMP led to higher fluxes in both cases, as expected, since there is an increase in the process' driving force in this case. At 0.8 and 0.6 bar, the M1 membrane exhibited an initial rapid decrease of fouling (in the first 10 minutes), followed by a slighter decrease (until approximately $50 \mathrm{mins}$ of filtration) and then stabilized. The first stage of flux decrease was softer for the 0.4 bar, and a flux stabilization directly followed it.

One possible explanation for the differences in behavior between the pressures is that for lower pressures (e.g., 0.4 bar), the driving force may lead to less droplet deformation or penetration into the pores, resulting in less severe fouling and an absence of the rapid flux decline stage.

Consequently, it can be inferred that for higher oil concentrations, the oil droplets quickly penetrate the

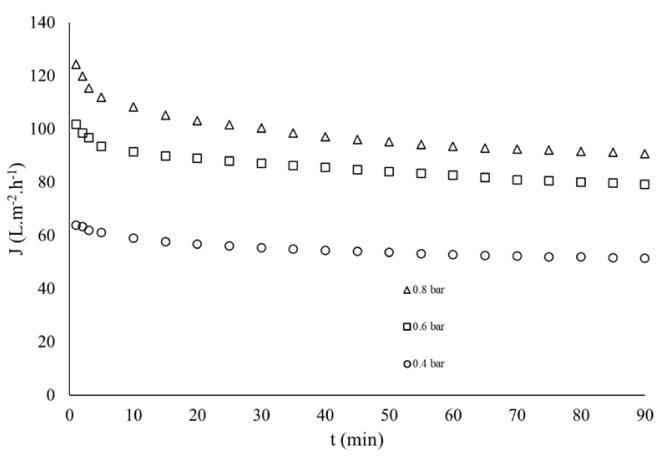

Figure 8. Variation of permeate flux with time at various operating conditions for the M1 membrane.

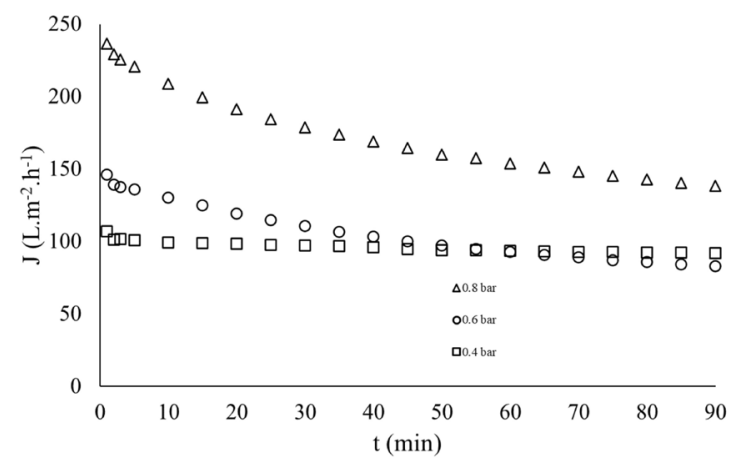

Figure 9. Variation of permeate flux with time at various operating conditions for the M2 membrane. 
membrane pores at the beginning of the filtration, partially obstructing them. With fewer available pores, the particles may start to form a cake layer in the second stage of flux decline, implying an additional resistance to the filtration media. Finally, the cake layer is already formed in the third stage, and the shear forces imposed by the tangential flux may favor the particle back transport at the same rate as particle deposition, reaching a steady state.

The same behavior is observed in membrane M2, but the time to reach a steady state is longer (for 0.6 and 0.8 bar), implying a slower particle deposition. It is worth noting that the observed fluxes are much higher for all pressure conditions. Thus, it can be hypothesized that because the M2 membrane has a larger mean pore size and a broader pore $\mathrm{SD}$, oil particles may be passing through the pores, which would imply a higher TOC content in the permeate. Another possibility is that as the two membranes are

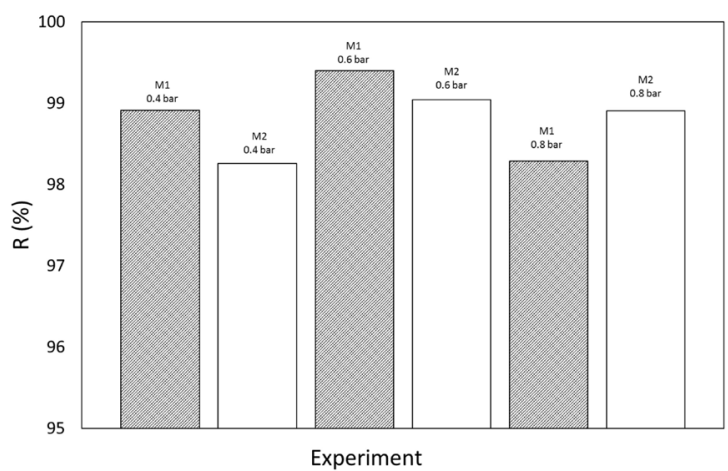

Figure 10. TOC removal in different pressures for M1 and M2 membranes. made from different materials (resulting from the thermal modification of the clay), the M2 membrane has less affinity with the solute, preventing oil droplets from penetrating the membrane pores and accumulating at the membrane surface.

\subsubsection{TOC removal}

Figure 10 shows the TOC removal (from the end of the experiment) in the M1 and M2 membranes at different pressures.

Figure 10 reveals that there was no loss of efficiency for the different pressures and that the TOC removal was over $98 \%$. Although the TOC removal is similar between the membranes, there is a difference in the oil droplet size in the permeate, as depicted by Figure 11. The M2 membrane has a smaller oil droplet size than the M1 membrane despite having a larger pore size and a broader pore SD.

Oil droplets easily adhere to the membrane surface resulting in the formation of the cake layer. Even if the size of the oil droplets is much larger than the membrane pore diameter under the applied high pressure, the oil droplets can be squeezed into and through the membrane nels ${ }^{46}$.

Thus, we can conclude that the M2 membrane's considerably higher fluxes were not due to the greater passage of the oil droplets' amount owing to its larger pores and broader pores SD (i.e., a lack of selectivity was not observed for M2 membrane). Both membranes presented similar rejections, and M2 membranes allowed the passage of smaller oil droplets. The difference in the materials of the membranes (caused by the thermal treatment) could be one explanation for the higher fluxes. As already stated in the literature, the oil release depends on the pore size as well as on the surface properties $^{47}$. In our case, since the M2 membrane is made of a different material, it may present a better interaction

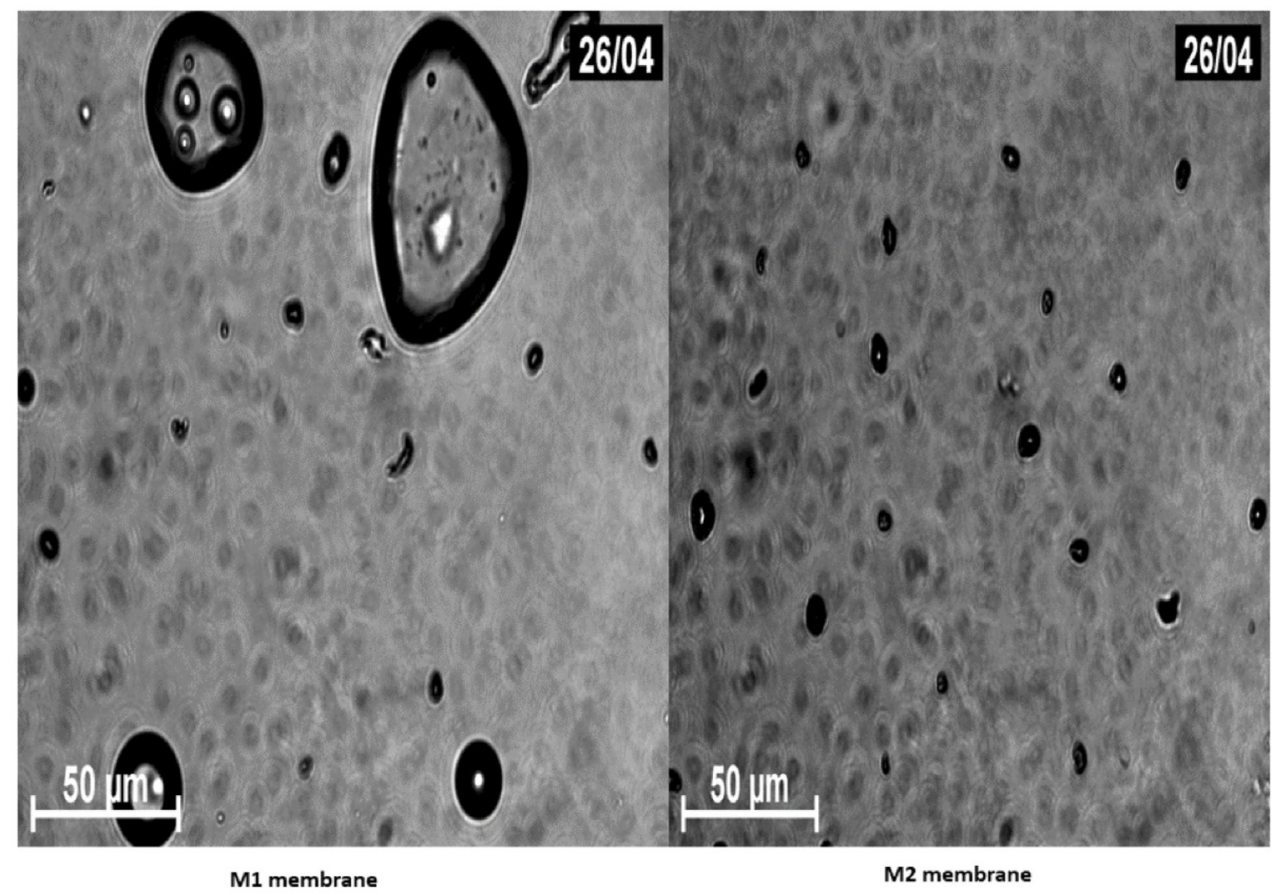

Figure 11. Microscopic analysis of the permeate after microfiltration for M1 and M2 membranes, in 0.6 bar. 
between the membrane and the oil droplets (less affinity and consequently less tendency of particle attachment and fouling) and a better affinity with water. These observations corroborate that the M2 membrane takes longer to achieve steady-state flux (possibly caused by the slower attachment/ faster detachment of the oil droplets). Further research and analysis are required to confirm these possible interactions.

\subsubsection{Total fouling resistance}

The TMP had a significant influence on the total fouling resistance. The membrane resistance increased with time (Figures 12 and 13), as demonstrated from the results. For both membranes, lower pressures exhibited better antifouling properties than higher pressures. The total membrane fouling resistance increased with filtration time, and the membranes in a subcritical condition showed better antifouling properties than in a super-critical condition although they had a lower $R_{t}$ value at the initial filtration stage, according to Jiang et al..$^{48}$.

Dilaver et al. ${ }^{49}$ verified that the total resistance $\left(\mathrm{R}_{\mathrm{T}}\right)$ values increased with decreasing membrane pore sizes for dispersed printing washing-baths mix and mixed hot wastewater. Similar behavior is observed in our results, where the M2 membrane has a larger pore size than the M1 membrane. Therefore, the M2 membrane had a lower total resistance.

\subsubsection{Determination of fouling mechanism}

Table 2 lists the model parameters estimated by fitting the model to the experimental data from Figures 8 and 9, together with their expanded uncertainties. As shown, the cake filtration model offers the best fit with the obtained experimental data. For both membranes, the cake poreblocking coefficient $(\mathrm{k})$ is higher at lower pressures than at higher pressures ( 0.6 and 0.8 bar). The M2 membrane had a cake pore-blocking coefficient (k) smaller than the M1 membrane.

Cake filtration has been reported as the most suitable or dominant fouling mechanism in a large portion of the literature on oil-in-water separations.

Complete blocking $(\mathrm{n}=2)$, standard blocking $(\mathrm{n}=1.5)$, intermediate blocking $(n=1)$, and cake filtration $(n=0)$ are the four mechanisms described in the literature.

Complete blocking occurs when the particle sizes are larger than the membrane pore size. The particles reach the membrane surface and seal the membrane pores, preventing superimposition on each other. The area of the blocked surface is proportional to the volume of the permeate.
In the intermediate blocking model, the particle sizes are similar to the membrane pore size. The number of pores or blocked surface area is also assumed to be proportional to the permeate volume but is less restrictive, such that not all particles necessarily block the pores and can settle on top of other particles. According to the standard blocking model, particles are smaller than the membrane pore size and can enter most pores and settle on the pore walls, reducing the pore volume. The decrease in the pore volume is proportional to the permeate volume. The cake filtration model explains the case of large particles that cannot enter the majority of pores and thus deposit a "cake" on the membrane surface $e^{41,50}$. The mechanism of cake formation considers the deposition

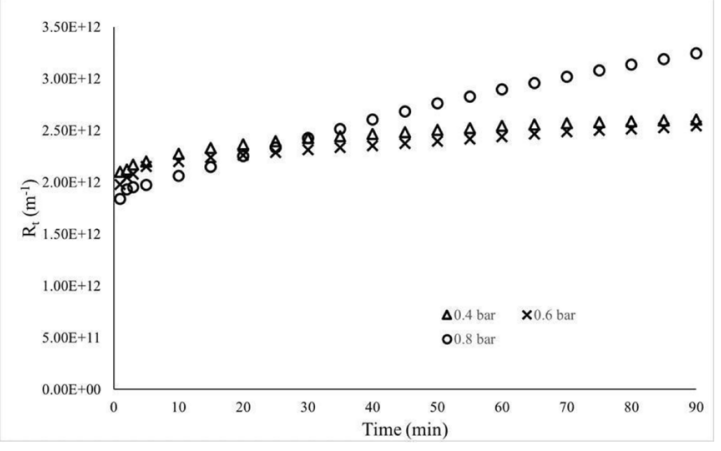

Figure 12. Total fouling resistance with the variation of time for M1 membrane.

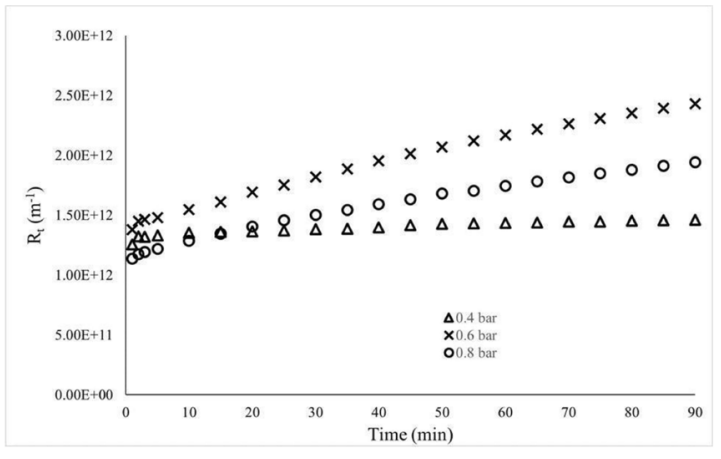

Figure 13. Total fouling resistance with the variation of time for M2 membrane.

Table 2. Estimated parameters of the model.

\begin{tabular}{|c|c|c|c|c|}
\hline \multicolumn{5}{|c|}{ M1 membrane } \\
\hline$\Delta \mathrm{P}$ (bar) & $\mathrm{k} \times 10^{-4}\left(\mathrm{sm}^{-2}\right)$ & $\mathrm{n}$ & Uncertainty* (x 10-4) & $\mathrm{R}^{2}$ \\
\hline 0.4 bar & 267 & 0 & 57 & 0.99 \\
\hline 0.6 bar & 118 & 0 & 72 & 0.95 \\
\hline 0.8 bar & 19.8 & 0 & 9.0 & 0.99 \\
\hline \multicolumn{5}{|c|}{ M2 membrane } \\
\hline$\Delta \mathrm{P}($ bar $)$ & $\mathrm{kx} 10^{-4}\left(\mathrm{sm}^{-2}\right)$ & $\mathrm{n}$ & Uncertainty* $\left(\mathrm{x} 10^{-4}\right)$ & $\mathrm{R}^{2}$ \\
\hline 0.4 bar & 104 & 0 & 37 & 0.97 \\
\hline 0.6 bar & 19.4 & 0 & 6.1 & 0.99 \\
\hline 0.8 bar & 10.3 & 0 & 2.3 & 0.99 \\
\hline
\end{tabular}

\footnotetext{
*Expanded uncertainty with a 95\% confidence level.
} 
of particles on the membrane surface as an additional porous layer with its resistance; in oily water systems, considering the depositions of oil droplets on the membrane surface as another porous layer with extra resistance may be questionable ${ }^{51}$.

\section{Conclusion}

Surface analysis of two ceramic membranes (M1 and M2) prepared with modified clays in the separation of an oil-in-water emulsion was successfully performed. Both membranes had eggshell residue and cationic manioc starch as additives. The thermal treatment of the clay for the M2 membrane is the main difference between the two membranes. AFM, contact angle, and mercury porosimetry analyses revealed that there were changes on the membrane surface that improved the microfiltration of the oil-inwater emulsion. The critical flux behavior at different oil concentrations varied significantly using the ceramic membranes and was consistent with the surface analysis. The M2 membrane provided a good combination of rejection, permeate flux, and lower resistance. According to the fouling mechanism analysis of different pore blocking models, the cake filtration model is most suitable for representing the experimental data of the membranes. The M2 membrane had a lower cake pore-blocking coefficient $(\mathrm{k})$ compared with the M1 membrane. In summary, a simple process (thermal treatment) was employed to modify the M2 membrane, allowing for an increase in the permeate flux and a lower resistance in the filtration of oil-in-water emulsions.

\section{Acknowledgments}

The authors acknowledge with gratitude the support of the Brazilian National Council of Scientific and Technological Development - CNPq Projects 425125/2018-1, 454669/20143. They also thank the Federal University of Paraná (UFPR) and Technology Sector from UFPR for infrastructural support. AFM Shimadzu at the Institute of Physics (INFIS/ UFU) supported by the grant "Pró-Equipamentos" from the Brazilian Agency CAPES.

\section{References}

1. Abadi SRH, Sebzari MR, Hemati M, Rekabdar F, Mohammadi T. Ceramic membrane performance in microfiltration of oily wastewater. Desalination. 2011;265(1-3):222-8.

2. Kayvani Fard A, Bukenhoudt A, Jacobs M, McKay G, Atieh MA. Novel hybrid ceramic/carbon membrane for oil removal. J Membr Sci. 2018;559:42-53.

3. Nandi BK, Uppaluri R, Purkait MK. Treatment of oily waste water using low-cost ceramic membrane: flux decline mechanism and economic feasibility. Sep Sci Technol. 2009;44(12):284069.

4. Iulianelli A, Drioli E. Membrane engineering: latest advancements in gas separation and pre-treatment processes, petrochemical industry and refinery, and future perspectives in emerging applications. Fuel Process Technol. 2020;206:106464.

5. Biron DS, Zeni M, Bergmann CP, Santos V. Analysis of composite membranes in the separation of emulsions sunflower oil/water. Mater Res. 2017;20(3):843-52.

6. da Silva Barbosa Ferreira R, Oliveira SSL, Salviano AF, Araújo EM, Leite AMD, de Lucena Lira H. Polyethersulfone hollow fiber membranes developed for oily emulsion treatment. Mater Res. 2019;22:1.
7. Shi Z, Zhang W, Zhang F, Liu X, Wang D, Jin J, et al. Ultrafast separation of emulsified oil/water mixtures by ultrathin freestanding single-walled carbon nanotube network films. Adv Mater. 2013;25(17):2422-7.

8. Jafari B, Abbasi M, Hashemifard SA. Development of new tubular ceramic microfiltration membranes by employing activated carbon in the structure of membranes for treatment of oily wastewater. J Clean Prod. 2020;244:118720.

9. Zhu L, Chen M, Dong Y, Tang CY, Huang A, Li L. A low-cost mullite-titania composite ceramic hollow fiber microfiltration membrane for highly efficient separation of oil-in-water emulsion. Water Res. 2016;90:277-85.

10. Tsuru T, Narita M, Shinagawa R, Yoshioka T. Nanoporous titania membranes for permeation and filtration of organic solutions. Desalination. 2008;233(1-3):1-9.

11. Song C, Wang T, Pan Y, Qiu J. Preparation of coal-based microfiltration carbon membrane and application in oily wastewater treatment. Separ Purif Tech. 2006;51(1):80-4.

12. Abbasi M, Mirfendereski M, Nikbakht M, Golshenas M, Mohammadi T. Performance study of mullite and mullitealumina ceramic MF membranes for oily wastewaters treatment. Desalination. 2010;259(1-3):169-78.

13. Nandi BK, Moparthi A, Uppaluri R, Purkait MK. Treatment of oily wastewater using low cost ceramic membrane: comparative assessment of pore blocking and artificial neural network models. Chem Eng Res Des. 2010;88(7):881-92.

14. Souza MYM, Lira HL, Santana LNL, Rodríguez MA. Preparation and application in crude oil-water separation of clay-based membranes. Mater Res. 2021;24(4):e20200508.

15. Ferreira EP, Bessa LP, Cardoso VL, Reis MHM. Influence of sintering temperature on the morphology of ceramic hollow fibers prepared from niobium pentoxide. Int J Appl Ceram Technol. 2019;16(2):781-90.

16. Vasanth D, Pugazhenthi G, Uppaluri R. Cross-flow microfiltration of oil-in-water emulsions using low cost ceramic membranes. Desalination. 2013;320:86-95.

17. Fard AK, Bukenhoudt A, Jacobs M, McKay G, Atieh MA. Novel hybrid ceramic/carbon membrane for oil removal. J Membr Sci. 2018;559:42-53.

18. Mouiya M, Bouazizi A, Abourriche A, Benhammou A, El Hafiane Y, Ouammou M, et al. Fabrication and characterization of a ceramic membrane from clay and banana peel powder: application to industrial wastewater treatment. Mater Chem Phys. 2019;227:291-301.

19. Liu N, Lin X, Zhang W, Cao Y, Chen Y, Feng L, et al. A pure inorganic $\mathrm{ZnO}-\mathrm{Co} 3 \mathrm{O} 4$ overlapped membrane for efficient oil/water emulsions separation. Sci Rep. 2015;5:1.

20. Qin D, Liu Z, Bai H, Sun DD, Song X. A new nano-engineered hierarchical membrane for concurrent removal of surfactant and oil from oil-in-water nanoemulsion. Sci Rep. 2016;6(1):24365.

21. Alresheedi MT, Basu OD, Barbeau B. Chemical cleaning of ceramic ultrafiltration membranes - Ozone versus conventional cleaning chemicals. Chemosphere. 2019;226:668-77.

22. Zhou M, Mattsson T. Effect of crossflow regime on the deposit and cohesive strength of membrane surface fouling layers. Food Bioprod Process. 2019;115:185-93.

23. Bacchin P, Aimar P, Sanchez V. Model for colloidal fouling of membranes. AIChE J. 1995;41(2):368-76.

24. Henriques JDO, Pedrassani M, Klitzke W, Mariano AB, Vargas JVC, Vieira RB. Thermal treatment of clay-based ceramic membranes for microfiltration of Acutodesmus obliquus. Appl Clay Sci. 2017;150:217-4.

25. Henriques JDO, Pedrassani MW, Klitzke W, Oliveira TV, Vieira $\mathrm{PA}$, Mariano AB, et al. Fabrication and characterization of low cost ceramic membranes for microfiltration of Acutodesmus obliquus using modified clays. Rev Matéria. 2019;24(4):1-12.

26. Xavier LA, de Oliveira TV, Klitzke W, Mariano AB, Eiras D, Vieira RB. Influence of thermally modified clays and inexpensive 
pore-generating and strength improving agents on the properties of porous ceramic membrane. Appl Clay Sci. 2019;168:260-8.

27. Sanalkumar KUA, Yang E-H. Self-cleaning performance of nano-TiO2 modified metakaolin-based geopolymers. Cement Concr Compos. 2021;115:103847.

28. Simon S, Nenningsland AL, Herschbach E, Sjöblom J. Extraction of basic components from petroleum crude oil. Energy \& Fuels. 2010;24(2):1043

29. Choobar BG, Alaei Shahmirzadi MA, Kargari A, Manouchehri M. Fouling mechanism identification and analysis in microfiltration of laundry wastewater. J Environ Chem Eng. 2019;7(2):103030.

30. Corbatón-Báguena MJ, Vincent-Vela MC, Gozálvez-Zafrilla JM, Álvarez-Blanco S, Lora-García J, Catalán-Martínez D. Comparison between artificial neural networks and Hermia's models to assess ultrafiltration performance. Separ Purif Tech. 2016;170:434-44.

31. Vincent Vela MC, Álvarez Blanco S, Lora García J, Bergantiños Rodríguez E. Analysis of membrane pore blocking models adapted to crossflow ultrafiltration in the ultrafiltration of PEG. Chem Eng J. 2009; 149(1-3):232-41.

32. Bainy EM, Lenzi EK, Corazza ML, Lenzi MK. Mathematical modeling of fish burger baking using fractional calculus. Therm Sci. 2017;21(1):41-50.

33. Nandi BK, Uppaluri R, Purkait MK. Preparation and characterization of low cost ceramic membranes for micro-filtration applications. Appl Clay Sci. 2008;42(1-2):102-10.

34. Chen RP, Liu XY, Yang W, Xia Z, Kang X, Lushnikova A. Wetting behavior of metakaolinite on the basal surfaces - Molecular dynamics study. Comput Geotech. 2021;129:103863.

35. Barbosa AS, Barbosa AS, Barbosa TLA, Rodrigues MGF, Synthesis of zeolite membrane (NaY/alumina): effect of precursor of ceramic support and its application in the process of oil-water separation. Separ Purif Tech. 2018;200:141-54.

36. Kayvani Fard A, Bukenhoudt A, Jacobs M, McKay G, Atieh MA. Novel hybrid ceramic/carbon membrane for oil removal. J Membr Sci. 2018;559:42-53.

37. Hubadillah SK, Othman MHD, Ismail AF, Rahman MA, Jaafar J. A low cost hydrophobic kaolin hollow fiber membrane (h-KHFM) for arsenic removal from aqueous solution via direct contact membrane distillation. Separ Purif Tech. 2019;214:31-9.

38. Yan L, Li YS, Xiang CB, Xianda S. Effect of nano-sized A12O3-particle addition on PVDF ultrafiltration membrane performance. J Membr Sci. 2006;276(1-2):162-7. http://dx.doi. org/10.1016/j.memsci.2005.09.044.

39. Usman J, Othman MHD, Ismail AF, Rahman MA, Jaafar J, Raji YO, et al. An overview of superhydrophobic ceramic membrane surface modification for oil-water separation. J Mater Res Technol. 2021;12:643-67.

40. Wenzel RN. Resistance of solid surfaces to wetting by water. Ind Eng Chem. 1936;28(8):988-94.

41. Fang J, Qin G, Wei W, Zhao X, Jiang L. Elaboration of new ceramic membrane from spherical fly ash for microfiltration of rigid particle suspension and oil-in-water emulsion. Desalination. 2013;311:113-26.

42. Field RWW, Wu D, Howell JAA, Gupta BBB. Critical flux concept for microfiltration fouling. J Membr Sci. 1995;100(3):259-72.

43. Bacchin P, Aimar P, Field R. Critical and sustainable fluxes: theory, experiments and applications. J Membr Sci. 2006;281(12):42-69.

44. Miller DJ, Kasemset S, Paul DR, Freeman BD. Comparison of membrane fouling at constant flux and constant transmembrane pressure conditions. J Membr Sci. 2014;454:505-15.

45. Tanudjaja HJ, Tarabara VV, Fane AG, Chew JW. Effect of cross-flow velocity, oil concentration and salinity on the critical flux of an oil-in-water emulsion in microfiltration. J Membr Sci. 2017;530:11-9.

46. Zhou JE, Chang Q, Wang Y, Wang J, Meng G. Separation of stable oil-water emulsion by the hydrophilic nano-sized $\mathrm{ZrO} 2$ modified A12O3 microfiltration membrane. Separ Purif Tech. 2010;75(3):243-8.

47. Suresh K, Pugazhenthi G. Cross flow microfiltration of oil-water emulsions using clay based ceramic membrane support and TiO2composite membrane. Egypt J Pet. 2017;26(3):679-94.

48. Jiang S, Zhang Y, Zhao F, Yu Z, Zhou X, Chu H. Impact of transmembrane pressure (TMP) on membrane fouling in microalgae harvesting with a uniform shearing vibration membrane system. Algal Res. 2018;35:613-23.

49. Dilaver M, Hocaoğlu SM, Soydemir G, Dursun M, Keskinler B, Koyuncu İ, et al. Hot wastewater recovery by using ceramic membrane ultrafiltration and its reusability in textile industry. J Clean Prod. 2018;171:220-33.

50. Mohammadi T, Kazemimoghadam M, Saadabadi M. Modeling of membrane fouling and flux decline in reverse osmosis during separation of oil in water emulsions. Desalination. 2003;157(13):369-75.

51. Salama A, Zoubeik M, Henni A, El Amin M. A new modeling approach for flux declining behavior during the filtration of oily-water systems due to coalescence and clustering of oil droplets: experimental and multicontinuum investigation. Separ Purif Tech. 2019;227:115688. 